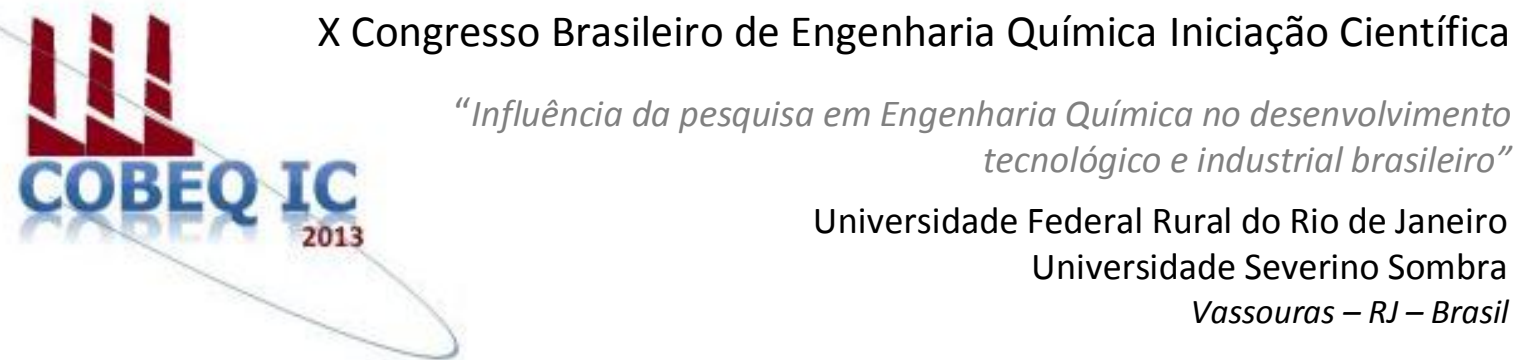

\title{
AVALIAÇÃO QUALITATIVA DA FULIGEM DISPERSA DE INDÚSTRIAS NA REGIÃO DE ITAJÁ/RN
}

\author{
REZENDE $^{1}$, A. C. C.; REBOUÇAS ${ }^{1}$, E.G; RODRIGUES ${ }^{2}$, M. V.; MEDEIROS $^{3}$, V. R. R.; \\ SOUSA ${ }^{4}$, M. A. S. B. \\ ${ }^{1}$ Aluna do DEQ/UFRN $\quad{ }^{2}$ Aluno do DEQ/UFRRJ ${ }^{3}$ Aluno do DEQ/UFRRJ \\ ${ }^{4}$ Professora do DEQ/UFRRJ \\ Departamento de Engenharia Química - Universidade Federal do Rio Grande do Norte \\ Endereço - Campus Universitário - Lagoa Nova, Natal/RN - CEP: 59078-900 \\ E-mail: magnelica@eq.ufrn.br
}

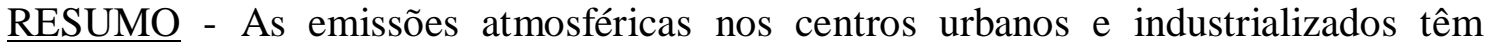
trazido inúmeros malefícios à saúde humana local. Além disso, essas emissões podem provocar problemas ambientais regionais e até mesmo globais. O material particulado, notadamente a fuligem, pode causar problemas às vias respiratórias, oftalmológicos e de natureza diversa. A avaliação da qualidade do ar é um instrumento importante para medidas de controle e gerenciamento das emissões bem como das atividades no ambiente. $\mathrm{O}$ presente trabalho visa avaliar qualitativamente a presença de fuligem nas proximidades de indústrias cerâmicas que usam lenha como combustível na região de Itajá/RN. Para realização do trabalho, foi realizado monitoramento visual e por papéis de filtro acomodados em dispositivo coletor. A amostragem foi realizada em batelada de $6 \mathrm{~h}$. Os filtros foram alocados a altura de $2 \mathrm{~m}$, e distante $300 \mathrm{~m}$ de uma chaminé de uma das indústrias presente no local. A observação visual verificou fumaça concentrada na saída das chaminés, mas que devido às condições climáticas rapidamente se dispersava na região. Os filtros não retiveram fuligem em quantidade, mas retiveram partículas de argila e poeira que também tem potencial nocivo a saúde.
\end{abstract}

Palavras chave: emissões atmosférica, indústrias de cerâmica, poluição.

\section{INTRODUÇÃO}

As emissões atmosféricas nos centros urbanos e industrializados têm trazido inúmeros malefícios à saúde humana local. Além disso, essas emissões podem provocar problemas ambientais regionais e até mesmo globais. O material particulado, notadamente a fuligem, pode causar problemas às vias respiratórias, oftalmológicos e de natureza diversa. A avaliação da qualidade do ar é um instrumento importante para medidas de controle e gerenciamento das emissões, bem como das atividades no ambiente; no entanto, ainda não é realizada com constância e os métodos utilizados são onerosos.

Os métodos para avaliação da qualidade do ar incluem o uso de amostradores 
de grande volume (que classifica o material particulado em termos de suas dimensões) e amostradores de gás. Entretanto, como ferramentas de avaliação preliminar, podem ser realizados diagnósticos por meio de aplicação de questionários e visitas in loco.

\section{OBJETIVO}

O presente trabalho visa avaliar qualitativamente a presença de fuligem nas proximidades de indústrias cerâmicas na região de Itajá/RN que usam lenha como combustível.

\section{ASPECTOS TEÓRICOS}

A economia do Rio Grande do Norte é baseada nas indústrias do turismo, produção de petróleo, agropecuária e cerâmica. No Estado, existem em operação quase 200 indústrias cerâmicas, das quais o maior número encontrase no Sérido, seguido pela região da Grande Natal e Baixo Assu. A região de Itajá (Baixo Assu) é conhecida pela qualidade de sua cerâmica vermelha, que produz telhas e tijolos. Em boa parte das indústrias, o combustível utilizado nos fornos ainda é a lenha (NASCIMENTO, 2007).

O uso da lenha traz problemas relativos à devastação da caatinga, além da geração de emissões atmosféricas, visto a queima da lenha produz monóxido de carbono e material particulado, nocivos à saúde humana e potenciais produtores de desequilíbrio ambiental.

Esforços têm sido empregados no sentido de minimizar o uso de lenha e na tentativa e qualificar e quantificar as emissões dessas indústrias. Apesar disso, as condições de operação das cerâmicas ainda geram muito desequilíbrio ambiental.

A queima da lenha como combustível gera uma pluma de poluentes que se dispersa no ar, de modo que o material particulado pode ocasionar problemas nas vias respiratórias.

Toda atividade antrópica produz resíduos que podem ter elevado ou menor potencial poluidor. Esses resíduos podem ser sólidos, líquidos ou gasosos. As emissões atmosféricas são resíduos lançados na atmosfera e podem se apresentar em quaisquer das três fases da matéria.

Entre as emissões atmosféricas encontram-se gases inorgânicos e orgânicos, gases do efeito estufa, compostos orgânicos voláteis (VOCs) e material particulado.

O material particulado em suspensão no ar varia de menos de $1 \mu \mathrm{g} / \mathrm{m}^{3}$ até 30000 $\mu \mathrm{g} / \mathrm{m}^{3}$ (SPIRO; STIGLIANI, 2009). Esse material, que aglomera sólidos e líquidos finamente divididos, é constituído de bactérias, fungos, vírus, cloreto de sódio, partículas do solo, poeira cósmica, fuligem, entre outros.

A atmosfera é composta por nitrogênio, oxigênio, vapor de água, $\mathrm{CO}_{2}$, gases nobres, poeira, pólen, micro-organismos. A poluição ocorre quando as proporções naturais são alteradas e ou surgem outros compostos que não estão normalmente presentes. Esse desequilíbrio ocorre devido ao lançamento de emissões pelas indústrias, carros e atividades humanas quaisquer.

Segundo Geng et. al (2008), a poluição do ar é um dos problemas centrais do presente século e os principais poluentes presentes na atmosfera das grandes cidades são os SOx, NOx, CO, VOCs, óxidos metálicos e aerossóis.

Ting et. al (2009) destacam a necessidade de se conhecer os perfis de concentração e transporte mecânico dos VOCs e apontam a escassez de informação sobre a presença desses compostos em regiões remotas.

Os aerossóis podem trazer problemas diretos à saúde da população, afetando o trato respiratório. Em termos ambientais, a presença de particulados na atmosfera aumenta a absorção da radiação solar e contribui fortemente para o aquecimento atmosférico por radiação (GOGOI et. al, 2013), ao passo que a queima incompleta de combustíveis aumenta a concentração de aerossóis na atmosfera, de fuligem e monóxido.

\section{METODOLOGIA}

O trabalho foi realizado na região do Baixo Assu, município de Itajá, que se caracteriza pelo clima semiárido, com 
temperaturas elevadas, escassas precipitações pluviais e baixa umidade do ar.

Para realização do trabalho, foi realizado monitoramento visual e por papéis de filtro acomodados em dispositivo coletor. A amostragem foi realizada em batelada de 6 h. Os filtros foram alocados a altura de $2 \mathrm{~m} \mathrm{e}$ distante $300 \mathrm{~m}$ do local de emissão.

Durante a permanência dos filtros, fezse observação visual da pluma de emissão e registro por meio de fotografia.

As condições climáticas no período apresentaram suas características normais, similares à média da estação para o ano de 2013.

\section{RESULTADOS E DISCUSSÕES}

A observação visual verificou fumaça preta concentrada na saída das chaminés e que, devido às condições climáticas, rapidamente se dispersava na região, de modo que a pluma ficava pouco concentrada a poucos metros de distância da fonte de emissão. As Figuras de 1 a 3 mostram as características da pluma de uma das cerâmicas que usa lenha como combustível.

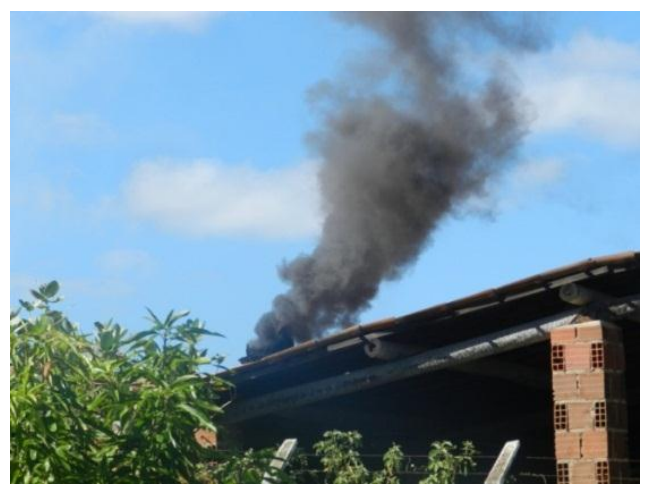

Figura 1: Característica de emissão na saída da chaminé

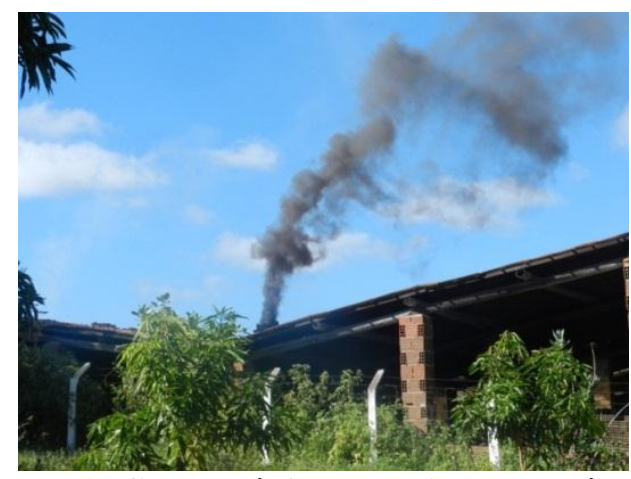

Figura 2: Característica da emissão na saída da chaminé.

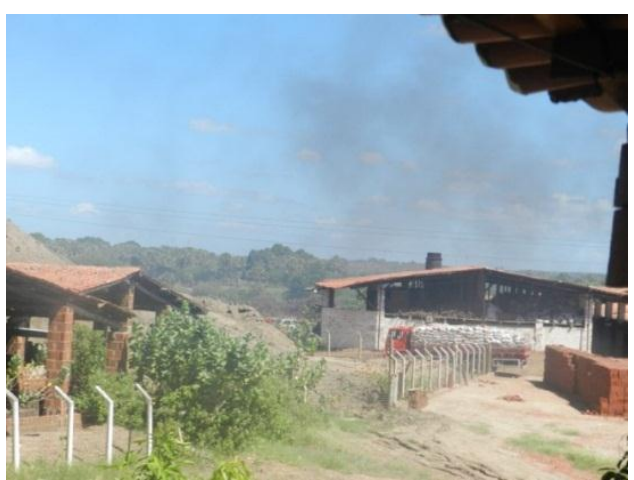

Figura 3: Dispersão da pluma

Os filtros alocados não conseguiram reter a fuligem por não possuírem um sistema de sucção como nos amostradores de grande volume. Além disso, devido à dispersão da fumaça e fuligem, a concentração que chega ao nível do solo é baixa e não consegue ser visualizada (como pode ser verificado na Figura 3), apenas sentida. Assim, o que pode ser captado pelos filtros é praticamente poeira e argila. $\mathrm{O}$ aspecto dos filtros após o monitoramento pode ser observado na Figura 4.

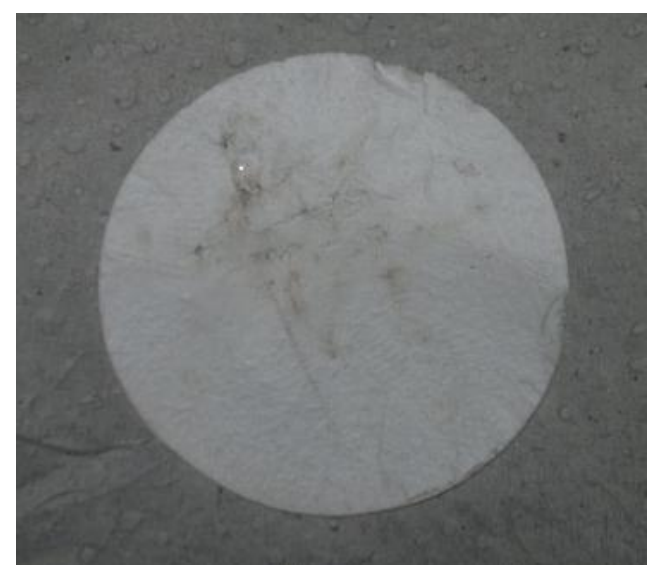

Figura 4: Filtro utilizado (especificação do filtro: membrana Milipore 0,45microns).

Apesar de não ser possível visualizar a fuligem nos filtros, é bastante forte na região o odor de fumaça, indicando que as emissões chegam às vias respiratórias dos moradores da região, mesmo ocorrida a difusão. Isto causa desconforto às vias aéreas dos habitantes e visitantes da cidade e possíveis efeitos crônicos àqueles que são expostos a contato prolongado, como os trabalhadores das indústrias ceramistas. 


\section{CONCLUSÃO}

Os filtros não retiveram fuligem em quantidade, mas retiveram partículas de argila e poeira que também tem potencial nocivo à saúde.

A percepção da emissão das indústrias de cerâmicas pelo olfato e garganta indica que, apesar da altura das chaminés e dispersão da fumaça, essas emissões chegam às vias respiratórias e podem provocar problemas respiratórios, entre outros.

\section{REFERÊNCIAS}

GENG, F., TIE, X., XU, J., ZHOU, G., PENG, L., GAO, W., TANG, X., ZHAO, C. (2008), "Characterizations of ozone, NOx, and VOCs measured in Shanghai, China". Atmospheric Environment, 42, 6873-6883.

GOGOI, M. M., BABU, S. S., MOORTHY, K. K., MANOJ, M. R., CHAUBEY, J. P. (2013), "Absorption characteristics of aerosols over the northwestern region of India: Distinct seasonal signatures of biomass burning aerosols and mineral dust". Atmospheric Environment, 73, 92-102.

NASCIMENTO, W. S. A. (2007), Avaliação dos impactos ambientais gerados por uma indústria cerâmica típica da região do Seridó/RN. Dissertação (Mestrado). Programa de Pós-Graduação em Engenharia Mecânica/UFRN.

SPIRO, T. G., STIGLIANI, W. M. (2009), Química Ambiental. Pearson Pretince Hall, $2 \mathrm{a}$. ed., São Paulo, SP.

TING, M., YUE-SI, M., HONG-HUI, X., JIE, J., FANG-KUN, W., XIAO-BIN, W. (2009), “A study of the atmospheric VOCs of Mount Tai in June 2006". Atmospheric Environment, 43, 2503-250 